\title{
Insurmountable Gap-- The Embodiment of Confucian Morality in Landscape Painting
}

Jiang Runyu.

\begin{abstract}
School of Fine Arts, Hunan normal University, Yuelu District, Changsha City, Hunan Province, China. 931473698@qq.com.
\end{abstract}

\begin{abstract}
The creation of Chinese landscape painting is described through the content and form of its picture, which often contains the values and spirit of the author and his contemporaries, as well as the moral concept of the era in which the author lives. It is through its unique form of expression and carefully intercepted picture content that landscape painting also plays its educational function in the process of history.

The Picture of Journey through Brooks and Mountains is Fan Kuan's masterpiece (950-1032). This paper analyzes the ideological background, expressive techniques, constituent elements and picture content, and excavates the moral ideas hidden in the picture narrative from the ideological dimension of Confucian ethics.
\end{abstract}

Keywords: landscape painting, morality, ethics, travel map of streams and mountains

\section{不可逾越的鸿沟一一儒家道德的山水画体现 \\ 江润宇}

\author{
中国湖南省长沙市岳麓区湖南师范大学美术学院 \\ 931473698@qq.com
}

\begin{abstract}
摘要
中国山水画的创作通过其画面内容与形式进行叙述，其中往往蕴含着作者及其同时代的价值观念与时代精神， 也无不显现着其作者所居时代的道德理念，正是通过其画面中独特的表现形式与精心截取的画面内容，山水画 在历史进程中也发挥着其教化功能。《溪山行旅图》为范宽 (950-1032) 的代表作，本文通过分析其中的思想背 景、表现技法、构成元素与画面内容并从儒家伦理教化的思想维度挖掘潜藏于本作画面叙事中的道德理念。
\end{abstract}

关键词：山水画，道德，伦理，溪山行旅图

\section{1. “中和” 文化结构带来的二元对立}

“道德” 的 “道” 指的是事物运动的规律， “德” 即德性, 指的是事物的本质与本性, 道德的所指即事 物发展的运行规律及本质问题。在中国古代社会发展 中, 儒家道德理念来自于上古时期对自然事物运动规 律的总结, 并将其运用在人的行为方式与社会关系方 面。中国的道德理念是建立在其宇宙观的基础上产生 的, 儒家思想作为自汉代罢黜百家独尊儒术以来支撑 中国传统封建社会的思想基石, 自孔子以来重视以周 礼为代表的社会秩序与仪式, 儒家的 “道德” 所指为
仪礼背后以 “仁” 的心理与情感为基础, 以 “礼” 的 目标与行为为指向, 遵守秩序与规则的自觉习惯。

“仁”与 “礼” 是儒家道德的来源与归宿, 孔子说 “君子之德风, 小人之德草”, 是指君子以自己的道 德品行推己及人, 道德的目的, 即是培养人 “非礼勿 视, 非礼勿听, 非礼勿言, 非礼勿动” 的潜在行为习 惯与准则。

儒家所倡的 “人与社会” 道德观念在山水画中 的体现与中国美学中的 “中和” 文化结构密切相关。 张法认为 “中和” 的审美观念源自于远古时期的 “立中” 仪式, 即立杆测影, 由立竿测影而来的宇宙 
的阴阳虚实观念在天地互动中被理解为以北辰为中 心、北斗为指引的气的运动，而人的社会与天地宇宙 同构, 社会运转的王权中心与天体运转的中心北斗相 同构。而这样的宇宙结构与人间秩序以等级为基础, 且人与人的社会地位并不平等, 帝王居于天下之中, 成为社会等阶中最高的存在, 君与臣民相对立, 儒家 道德观念中的 “道德” 具有一定的先验性: 君制定着 人间社会运转的规则与法度，而每个臣民应按照自身 所处的阶级行事, 天下事物都以先验的既定的合乎天 道的理想状态运行就是 “和” ，也即合于道德。“君 君臣臣父父子子” 的伦理关系逐渐固化, 皇家宫殿居 天下之中, 成为天下建筑的样板与法度。皇家审美也 因此居于最高位, 成为天下艺术作品审美体系中的典 范与目标。在这样的思想背景下, 山水画作品中也将 通过艺术形象的大小、位置、关系、空间等诸多因素 来体现人的社会中存在的伦理关系, 即对 “中” 的突 出, 画面中也存在 “统治”与 “服从”、“高位”与 “低位”、“中心”与 “边缘” 的一系列关系, 通过 这类画面关系体现人的社会关系, 而这样的对比也在 某种程度上契合了 “阴阳相成”、“虚实相生” 的宇 宙规律与中国美学观念。如北宋范宽的《溪山行旅图》, 表现的是关陕地方的山区景色, 由近处小人经过的溪 岸、树石、屋宇瀑布构成的前景与高等主山、两侧的 群山与飞瀑构成, 中间部分作者用留白的方式将前后 二景划开了一道不可逾越的鸿沟。画面正中的雄伟主 峰占据了画面的主体, 作者以简练概括、大小匀称排 布于山顶的树木与近景枝出叶繁、品类繁多且细致刻 画的树木对比以体现主峰与近景空间距离之遥远, 而 前景又以人物的极其渺小与自然景物之大进行比对。 前景的人物-自然之对比、前景与后景详-简之对比共 同构成了画面人物与画面主体山峰绝对的大小分别 - - 人如蝼蚁, 在主峰面前渺若蜉蝣。作者进行这样 的双重对比有着儒家道德观内涵, 其将人物处理得无 限渺小目的是突出后景主峰的巨大, 以人为尺度去度 量不可丈量的主峰。

\section{2. 符号演绎山水物象的道德内涵}

山水画是中国画中以山水题材进行分类的一支, 其中按绘画技法又可分为写意山水与工笔山水。山水 画作为以自然山川、河流、树石、草木等景物为主要 表现内容的艺术形式, 在历史进程中其不断发展演变, 形成了独特的表现技法、审美理念与美学价值。从现 存画像石与画像砖中我们可以得知在两汉时期山水 元素作为人物陪祄出现, 独立山水画与其审美体系形 成于魏晋南北朝时期, 在隋唐时期山水画技法与理论 逐步发展, 于宋元时期㿰法样貌基本完备, 达到高峰, 在明清时期因以 “四王” 为首的正统、拟古人的审美 倾向与以 “四僧” 为首的野逸、师造化的审美倾向相 对立而呈现出纷繁的多样面貌。山水画的画面内容、 表现技法与审美理念, 无不蕴藏着同一时期的道德理 念, 山水画也因其作者意识形态与审美理念或明或暗 的显现而起着社会教育的作用。
中国山水绘画, 在一定程度上延续了中国艺术物 象一归纳-推演的表达思路, 从自然物象中提炼物象的 本质形态将其归纳成为抽象符号, 再在此抽象符号的 基础上进行变化与推演, 并以此还原成人的视角下的 自然物象, 《周易》是这一物象一归纳-推演的早期形 态, 《说卦传》: “神也者, 妙万物而为言者也。动 万物者, 莫疾乎雷; 桡万物者, 莫疾乎风; 燥万物者, 莫熯乎火; 说万物者, 莫说乎泽; 润万物者, 莫润乎 水; 终万物、始万物者, 莫盛乎艮。故水火相逮, 雷 风不相悖, 山泽通气, 然后能变化, 既成万物也。” 表面其将天地自然万物归纳为一阴爻与阳爻通过不 同排列组合方式构成的乾、坤、震、艮、离、坎、兑、 巽八种代表自然物象的抽象理念, 再将八者叠加以推 演与预测事物的发展状态。山水绘画则继承这一 “物 象一归纳-推演” 的创作过程, 将自然山水的形态归纳 为树木、山石、云雾、河川等自然物象的符号, 再在 画面上将此类不同的自然物象符号以各异的方式叠 加与表现, 山水画由此成为山水物象的复现过程。但 在此复现的过程中，民族道德观念与时代道德观念影 响着山水物象符号的表现形态。在《溪山行旅图》中, 主峰及近景在位置、大小上都有所隐喻: 主峰的重点 刻画处一一其山形棱角与树木最为繁密处, 位于画幅 上半部分的正中位置; 近景的重点刻画处一一行人及 溪岸树石最为繁密处，位于画幅下半部分的正中位置。 这与《周易》中将二爻相叠加的对立统一同构: “天 尊地卑, 乾坤定矣。卑高以陈, 贵贱位矣。动静有常, 刚柔断矣。方以类聚, 物以群分, 吉凶生矣。在天成 象, 在地成形, 变化见矣”。周易将上下二爻叠加成 为一卦, 一阴一阳, 一动一静, 一尊一卑, 一刚一柔。 以 “乾” 卦为例: 乾卦的上爻中位九五爻辞为 “飞龙 在天, 利见大人”, 是龙腾飞于天的状态, “利见大 人” 的 “大人” 即与其相对的下卦中爻九二, 其爻辞 为 “见龙在田, 利见大人” , 即龙潜伏于田野中, “利 见大人” 即与其相对的上卦中爻九五。在这二者的相 对立中，居于上位的九五即阳、动、尊、刚的一端， 而居于下位的九二即阴、静、卑、柔的一端。在孔子 看来, “飞龙在天”与 “见龙再田” 二者的状态都属 于 “君德”, “同声相应, 同气相求。水流湿, 火就 燥, 云从龙, 风从虎, 圣人作而万物睹。本乎天者亲 上, 本乎地者亲下, 则各从其类也。”, 居于上位者 应于时间与空间的合宜而兴起，国家中的 “人王” 行 事的法则本乎于天，“王道” 源于 “天道” , “人王” 根据源于仰观天象俯察地理总结宇宙的变化与规律 来制定人世的规矩与法度, 其行事是 “天道” 在 “人 道” 中的显现。而居于下位者 “庸言之信, 庸行之谨, 闲邪存其诚，善世而不伐，德博而化” ，在平日的言 行中保持诚信与谨慎, 防范邪恶保持真诚, 善居于世 而不夸耀, 安于且居于 “克己” 与 “被统治” 的地位 并完善自身以使得自身的个人道德广博并得以显现。 


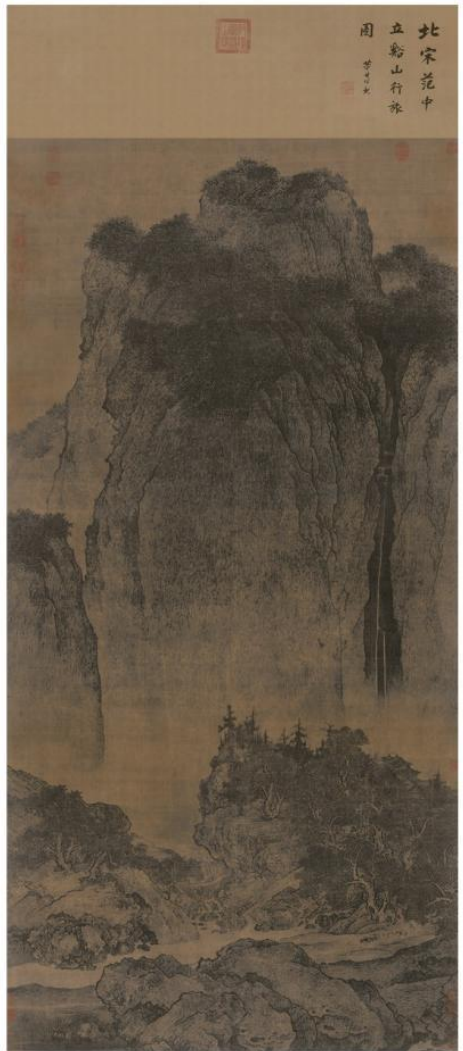

图 1 范宽《溪山行旅图》

\section{3. 儒家道德内涵在《溪山行旅图》的具体呈现}

在《溪山行旅图》中, 以压倒的气势、距离的深 远与空间上的极大极高营造出的主峰与乾卦中的九 五爻同构, “飞龙在天” 即龙腾飞于天, 主峰在画幅 中居于高位, 呈管立之态, 以其高䇯的姿态呈现强烈 的动势, 在观者看来以扑倒之势袭来, 又以其深远的 空间感离开观者向后倾斜, 成为营造画面动势的主势, 较底下的近景与两旁的群山而言占据了画面的绝对 动势。主峰䇯立于画面中上端与底端的近景相对如同 人间世的帝王自北而南临, 以其定位之高、体量之大 与气势之盛体现其 “尊” 的位置, 以最大最高最雄伟 的山形象征人间帝王拥有天下最大最多最高级的美, 彰显授命于天的帝王之性。以雄健冷峻的中锋用笔写 山形轮廓, 坚劲沉雄的雨点荦体现山性的雄厚刚毅体 现出明显的壮美感与崇高感。在近景处各显其貌的枝 桠林木在其雄壮的山体上显得平凡与一致, 山体的总 瞰使得形态各异的个体性、特殊性的林木树石成为普 遍性与一般性的存在, 是 “多” 归于”一 一的总结, 是以 “一” 的姿态统领全画物象之 “多” 的主导者、 统治者与引领者。郭熙指出: “大山堂堂, 为众山之 主, 所以分布以次冈林壑, 为远近大小之宗主也。其 象若大君, 赫然当阳, 而百辟奔走朝会, 无姮塞背却 之势也”, 主峰既是画面中众山之主, 成为次冈林壑 的宗主, 也象征着人间世的君王, 其下近景的树石草 木如同百官奔走于朝会之间, 而巍峨主峰成为 “君德” 的征象, 虽居于高位, 却无骄纵傲慢之姿态。居于阳 位, 处于显露、居正之位, 为全画之统率, 万象之中
心。

主峰无法仅凭借自身在画面中体现其阳、动、尊、 刚, 郭熙指出: “欲上有盖, 欲下有乘, 欲前有据, 欲后有倚, 欲下瞰而若临观, 欲下游而若指麾, 此山 之大体也”，阴阳相成是中国艺术的宇宙观与基本特 征, 主峰的存在必有所承载、有所对比、有所依据。 《溪山行旅图》中以近景的阴、静、卑、柔与主峰的 阳、动、尊、刚构成对立关系。在画面中居于下位, 着重笔墨描写姿态各异的山石、树木、溪流、楼宇、 人马等细致景色的近中景处, 其与乾卦中的九二爻同 构, “见龙再田” 即龙横卧与田野之中, 近景在整体 画面中呈横卧之态, 横卧于主峰等诸峰之下, 在空间 处理上一是突显主峰的高䇯, 以 “横” 的水平稳定反 祄 “坚” 的挺拔坚韧, 二是在近景与远景中形成往还 回荡的空间, 在画面的空间中, 近景的物象更为平易 近人, 与远景只能可观可望的深远距离感相异, 近景 陈于眼前有可居可游之意趣。观者的目光可以在近景 的繁密与远景的疏离中往返来回, 进一步增强了近景 与远景的对立。近景在画面中面积占比相对远景主峰 较小, 居于画幅底部一隅而仰远景主峰的高等巍峨, 如同人间世的臣子朝北而拜，而这也与日月众星环绕 位于极北的北辰运行的天体运行规律同构。与占据画 面主体而居于 “尊” 位的主峰相较, 近景以其定位之 低、体量之小与气势之柔体现其 “卑” 的位置, 在阴 阳中居于阴, 在刚柔中居于柔。在动静一方面中, 近 景有溪流之动、人马之动、风吹林木之动, 呈现出生 机勃勃的鲜活景象, 而与主峰从空间构成所营造出的 整体压迫之动势相较, 则处出于相对静止的姿态。坡 岸上的植被以软硬、浓淡、干湿各异的笔法绘制品类 不同、大小有别、高低错落、形态各异的草木，近景 山石的形态、阴阳、向背变化相较于远景主峰也更富 于变化, 细节更为丰富, 其间夹杂数条由远至近粗细 不同、高低参差的小瀑布, 与主峰旁侧一泻千里的狭 长瀑布形成鲜明对比。在近景之丰富细节与远景整体 气势的对比中, 近景是整体性的 “一” 在大千自然山 水世界之 “多” 的丰富推演, 是普遍性与一般性的山 水树石概念向个体性与特殊性的形态各异、细节丰富 的现实的演变, 是 “一”与 “多” 的对立中 “多” 的 一面。是以整体人间世普遍通行规律所演绎出的丰富 多姿的现实世界, 也象征着形态各异、各不相同、等 级相差的承载者、臣服者、被统治者。

\section{4. 结论}

范宽《溪山行旅图》中将画面主位之高峰与宾位 之近景划分开的是以留白方式显现出的一道鸿沟, 以 儒家道德理念的视角观之, 这一鸿沟划分的不仅是主 峰与近景的深远空间距离, 还有主峰所象征的 “人 王”、“尊位”、“君” 与近景所象征的 “臣民”、 “卑位” 等高低贵贱划分明确的社会阶层的不可逾 越性, 这种不可逾越进一步泛化成为对以社会身份所 形成的绝对权威的认同服从。因此《溪山行旅图》也 成为人间世高低贵贱等级森严的社会等级秩序以山 
水符号的象征性再现。《乐记・乐礼篇》中阐述了这 种在各类艺术形式中常见的高低、尊卑、贵贱相区别 的以 “礼” 为核心的价值观念与意识形态: “天尊地 卑, 君臣定矣。卑高已陈, 贵贱位矣。动静有常, 小 大殊矣。方以类聚, 物以群分, 则姓名不同矣。在天 成象, 在地成形, 如此, 则礼者天地之别也。”这与 范宽《溪山行旅图》中用山水的视觉符号所呈现出的 道德理念一致。郭熙认为: “山水, 先理会大山, 名 为主峰。主峰已定, 方作以次, 近者、远者、小者、 大者, 以其一境主之于此, 故曰主峰。如君臣上下也。” 在绘画构思上, 郭熙也认为 “观者先看气象, 后辨清 浊。分宾主之朝揖, 列群峰之威仪”, 就绘画功能论 而言, 《溪山行旅图》以其构图、笔墨、内容将象征 君王的主峰与象征臣民的近景相区分, 实现了张彦远 所言 “夫画者: 成教化, 助人伦” 的社会教化功能。 在观者的观画过程中, 观者面临巨嶂山水中主峰磅礴 气势时观者与主峰相对立, 在总览全做时画作构图中 近景与主峰相对立, 这双重对立构成了对观者主客、 尊卑、高下相分别的潜意识营造与深化作用, 将观者 询唤成为作为被统治者的社会主体, 从而实现对社会 伦理等级观念与制度的强化, 通过对人身份地位的尊 卑高下以维持与加强封建社会的稳定性。这种教化作 用最为明显地体现在以 “三纲” 为首的伦理纲常中, 《白虎通义》: “三纲者何谓也? 谓君臣、父子、夫 妇也。”画面中主峰与近景的对立, 在 “君臣” 关系 中体现为君对臣的统治与臣对君的服从; 在 “父子” 关系中体现为父对子的管教与子对父的听从; 在 “夫 妇” 关系中体现为夫对妇的扶接与妇对夫的屈从。通 过尊卑、主客、大小、高低二元对立的画面形式发挥 其道德教化功能, 强化对以 “君臣”、“父子”、“夫 妇” 为主的以高低等级划分的社会伦理关系的正当 性与合理性, 且这种等级秩序法天顺地地源自于 “阴 阳相成” 的宇宙观与源自天象观察经验总结的自然 运行规律, 因此将这种尊卑分明的社会伦理关系观念 化与神圣化, 从而维系了儒家以 “礼” 为核心以纲常 伦理社会关系为手段的封建统治。

\section{REFERENCES}

[1] Zhang, F. (2006) History of Chinese aesthetics. Sichuan people's Publishing House, Chengdu.

[2] Yu, J. (2015) A grand view of the theory of Chinese painting in the past dynasties. The first part, the Theory of painting from the pre-Qin Dynasty to the five dynasties. Jiangsu Phoenix Art Publishing House, Nanjing.

[3] Zhou, Z. (1991) Translation and Annotation of the Book of changes. Zhonghua Book Company, Beijing.

[4] Yu, J. (2015) A grand view of the theory of Chinese painting in the past dynasties. The second part, the theory of painting in the Song Dynasty. Jiangsu Phoenix Art Publishing House, Nanjing.

[5] Chen, L. (1994) Interpretation of Baihutong. Zhonghua Book Company, Beijing.

[6] Yang, B. (1980) Translation and Annotation of the Analects of Confucius. Zhonghua Book Company, Beijing.

[7] Wang, W.(2001) Translation and interpretation of the Book of Rites. Zhonghua Book Company, Beijing.

[8] Yang, Y. (2018) The form and Image Analysis of the Map of Journey through streams and Mountains. Art Magazine, 601: 134-135.

[9] Wu, J. (2006) Outside the creature, the heart source. appreciation of Fan Kuan's Picture of Journey through streams and Mountains. Cultural Relics of Central China, 130: 85-87. 